\title{
Baicalein induces cervical cancer apoptosis through the NF-kB signaling pathway
}

\author{
XIAOLAN YU ${ }^{1 *}$, YUQING LIU ${ }^{2 *}$, YONGZHOU WANG $^{1}$, XIGUAN MAO $^{3}$, YUJIAO ZHANG $^{3}$ and JIYI XIA ${ }^{2}$ \\ ${ }^{1}$ Department of Obstetrics and Gynecology, The Affiliated TCM Hospital of Southwest Medical University; \\ ${ }^{2}$ School of Medical Information and Engineering, Southwest Medical University; ${ }^{3}$ Department of Obstetrics and Gynecology, \\ The Affiliated Hospital of Southwest Medical University, Luzhou, Sichuan 646000, P.R. China
}

Received January 6, 2017; Accepted July 25, 2017

DOI: $10.3892 / \mathrm{mmr} .2018 .8493$

\begin{abstract}
To investigate the mechanism of baicalein in inducing human cervical cancer cell line C33A apoptosis. Baicalein $(200 \mu \mathrm{M})$ was used to treat C33A cells. Cell proliferation was tested by the MTT assay. Cell apoptosis was detected by the TUNEL assay and caspase-3 activity measurement. Cell cycle was determined by flow cytometry and associated gene expression at mRNA and protein levels. Nuclear factor (NF) $\kappa \mathrm{B}$ activity was assessed by luciferase assay and western blotting. Baicalein suppressed cervical cancer cell $\mathrm{C} 33 \mathrm{~A}$ proliferation and induced cell apoptosis by activating caspase- 3 activity. Baicalein blocked cell cycle in $G_{0} / G_{1}$ phase through regulating the expression of associated genes. Baicalein inhibited $\mathrm{NF}-\kappa \mathrm{B}$ activity by repressing nuclear translocation. Baicalein suppressed $\mathrm{C} 33 \mathrm{~A}$ proliferation and promoted cellular apoptosis by inhibiting $\mathrm{NF}-\kappa \mathrm{B}$ signaling pathway. In conclusion, the results indicate that baicalein can inhibit cervical cancer cell proliferation and promote cell apoptosis by affecting NF- $\mathrm{BB}$ activity.
\end{abstract}

\section{Introduction}

Uterine cervical cancer is a common malignancy in women, as well as breast cancer worldwide $(1,2)$. At present, surgery, chemotherapy and radiotherapy are the most widely applied strategies for cervical cancer treatment. Adjuvant or neoadjuvant radiotherapy or chemotherapy following surgical resection intend to restrain tumor cell proliferation and metastasis, whereas the largest drawback is that the healthy cells are also killed, leading to serious complications. As natural products are considered to be less toxic and lead to fewer side effects

Correspondence to: Dr Jiyi Xia, School of Medical Information and Engineering, Southwest Medical University, 319 Zhongshan Road, Luzhou, Sichuan 646000, P.R. China

E-mail: xiajiyi@swmu.edu.cn

${ }^{*}$ Contributed equally

Key words: cervical cancer, baicalein, $\mathrm{NF}-\kappa \mathrm{B}$, cell cycle, apoptosis than that of synthetic drugs, the potential anticancer properties of natural products have been previously investigated (3). Traditional Chinese medicines and their active constituents may serve a role in cancer treatment via numerous mechanisms, including the induction of apoptosis (4), blocking telomerase activity (5), suppressing angiogenesis (6), improving immune functions (7) and enhancing cytotoxicity (8). The majority of previous studies have focused on the effect of antitumor agents to react on tumor shrinkage or disappearance through inducing cancer cell apoptosis $(9,10)$.

Baicalein is a flavonoid derived from the root of Scutellaria baicalensis, presenting with a variety of biological activities, including antitumor, antimicrobial, anti-inflammatory and anti-ischemic properties (11-14). As a prospective anticancer drug, the beneficial effect of baicalein as a single or combined treatment is of significance. It has been reported that baicalein was involved in the inhibitinon of various types of cancer (including bladder cancer, breast cancer, colorectal cancer, gastric cancer, hepatocellular carcinoma, osteosarcoma, multiple myeloma, melanoma/skin cancer, ovarian cancer, pancreatic cancer, prostate cancer and lung cancer) (15). The key molecular mechanisms of the anti-tumor effects of baicalein include inhibiting several cyclins or cyclin-dependent kinases (CDKs) to regulate the cell cycle, scavenging oxidative radicals, attenuating mitogen-activated protein kinase, protein kinase B or mechanistic target of rapomycin activities, inducing apoptosis through activating caspase-9/-3 and inhibiting tumor invasion and metastasis by reducing the expression of matrix metalloproteinase 2/9 (15). However, the effects of baicalein on cervical cancer cells and the associated mechanisms remain to be fully elucidated.

In the present study, human cervical cancer C33A cells were used to explore the anticancer effect of baicalein in vitro. The effect of baicalein treatment on C33A cell proliferation was determined by the MTT assay. The current study investigated whether baicalein can induce C33A cell apoptosis by the terminal deoxynucleotidyl transferase (TdT) dUTP nick-end labeling (TUNEL) assay and caspase-3 activity measurement. Cell cycle changes of C33A cells following treatment with baicalein were evaluated by flow cytometry and associated genes expression. The activity of nuclear factor $(\mathrm{NF})-\kappa \mathrm{B}$ signaling pathway was measured by luciferase assay, reverse transcription-quantitative polymerase chain reaction 
(RT-PCR), and western blotting, in order to clarify the underlying mechanisms of baicalein-induced apoptosis in cervical cancer C33A cells.

\section{Materials and methods}

Cell line and reagents. The human cervical cancer cell line C33A was obtained from the Institute of Biochemistry and Cell Biology, Shanghai Institute of Biological Sciences, CAS (Shanghai, China). The cells were maintained in DMEM medium supplemented with $10 \%$ fetal calf serum, 100 U/ml penicillin (Sigma-Aldrich; Merck KGaA, Darmstadt, Germany) and $100 \mathrm{~g} / \mathrm{ml}$ streptomycin (Sigma-Aldrich; Merck $\mathrm{KGaA}$ ), and cultured at $37^{\circ} \mathrm{C}$ and $5 \% \mathrm{CO}_{2}$. Baicalein was obtained from Sigma-Aldrich (Merck KGaA) and dissolved in dimethyl sulfoxide (DMSO).

MTT assay. C33A cells in suspension were seeded into a 96-well plate. Baicalein was used to treat cells for different times with three replicates. Subsequently, $20 \mu 1$ MTT reagent (5 mg/ml, Invitrogen; Thermo Fisher Scientific, Inc., Waltham, MA, USA) was added to the well for $4 \mathrm{~h}$, then $150 \mu \mathrm{l}$ DMSO were used to dissolve the crystal substance. The plate was then read at $490 \mathrm{~nm}$ on a microplate reader to draw the proliferation curve.

$N F-\kappa B$-dependent reporter gene expression assay. Levels of $\mathrm{NF}-\kappa \mathrm{B}$ activity in $\mathrm{C} 33 \mathrm{~A}$ cells were assessed by the luciferase reporter assay. $\mathrm{NF}-\kappa \mathrm{B}$ luciferase constructs (\#CLS-013 L; SABioscience, Frederick, MD, USA) was stably transfected into C33A cells using Lipofectamine ${ }^{\circledR}$ (Invitrogen; Thermo Fisher Scientific, Inc.). In brief, C33A cells were treated with $200 \mu \mathrm{M}$ AgNPs for $24 \mathrm{~h}$, then the cells were washed with ice-cold PBS and harvested in 1X lysis buffer. Following centrifugation, $10 \mu \mathrm{l}$ supernatant was measured for luciferase activity with a luminometer (Turner Designs, Inc., Sunnyvale, CA, USA). The NF- $\kappa$ B-luciferase activity was monitored using the luciferase assay kits from Promega Corporation (Fitchburg, WI, USA). The luciferase activity was normalized against known protein concentrations and expressed as percentage of luciferase activity in the control cells.

TUNEL assay. C33A cells treated by $200 \mu \mathrm{M}$ baicalein for $24 \mathrm{~h}$ were stained using the ApopTag Fluorescein In Situ Apoptosis Detection kit (Chemicon International, Inc., Temecula, CA, USA), and apoptosis was observed using confocal laser scanning microscopy (TCS SP2; Leica Microsystems GmbH, Wetzlar, Germany).

Caspase-3 activity measurement. The activity of caspase-3-like protease in the C33A cells was assessed using a colorimetric caspase-3 assay kit (Sigma-Aldrich; Merck $\mathrm{KGaA}$ ) according to the manufacturer's protocol. In brief, $100 \mu \mathrm{l}$ reaction mixture containing $30 \mu \mathrm{l}$ cell lysate and $10 \mu \mathrm{l}$ caspase-3 substrate acetyl-Asp-Glu-Val-Asp-p-nitroanilide at $200 \mu \mathrm{M}$ in assay buffer was used, and the assay was performed in a 96-well plate. The mixture was incubated at $37^{\circ} \mathrm{C}$ for $90 \mathrm{~min}$ and the absorbance was measured at $405 \mathrm{~nm}$. The caspase-3 activity was calculated by value of OD 405 relative to the control.
Cell cycle detection. The cell cycle was detected using a cell cycle detection kit (KeyGen BioTec, Beijing, China). C33A cells in the logarithmic phase were seeded into 12-well plates and treated with $200 \mu \mathrm{M}$ baicalein for $24 \mathrm{~h}$. Subsequent to collection and washing twice with PBS, the cells were added to $1 \mathrm{ml} 70 \%$ precooled ethanol at $4^{\circ} \mathrm{C}$ overnight. Then the cells were washed by PBS and treated with $100 \mathrm{mg} / \mathrm{l}$ RNase at $37^{\circ} \mathrm{C}$ for $30 \mathrm{~min}$. After staining with $50 \mathrm{mg} / 1$ propidium iodide (PI) at $4^{\circ} \mathrm{C}$ in the dark for $30 \mathrm{~min}$, the cells were detected by flow cytometry with the excitation wavelength at $488 \mathrm{~nm}$. The primary result was analyzed by cell cycle matching software to record hypodiploid peak, namely sub- $G_{1}$ phase, $G_{0} / G_{1}$ phase, $\mathrm{S}$ phase and $\mathrm{G}_{2} / \mathrm{M}$ phase. All experiments were repeated a minimum of three times.

$R T$ - $q P C R$. Total RNA was extracted from C33A cells using TRIzol (Invitrogen; Thermo Fisher Scientific, Inc.) and reverse transcribed to cDNA using the K1622 kit (Fermentas; Thermo Fisher Scientific, Inc.). The primers used were designed by Primer 6.0. qPCR was applied to test target gene expression. The reaction conditions were as follows: $55^{\circ} \mathrm{C}$ for $1 \mathrm{~min}$, followed by 40 cycles of $94^{\circ} \mathrm{C}$ for $30 \mathrm{sec}, 55^{\circ} \mathrm{C}$ for $30 \mathrm{sec}$, and $72^{\circ} \mathrm{C}$ for $45 \mathrm{sec}$. GAPDH was applied as internal reference. The $2^{\Delta \triangle \mathrm{Cq}}$ method (16) was applied to calculate the relative expression levels. The primer sequences were as follows: p21, forward 5'-CCATCGGAATATGTACCGACTG-3' and reverse 5'-CTC AGCGGTCGTAATCTGTCA-3'; Bcl-2-like protein 11 (Bim), forward 5'-CATATAACCCCGTCAACGCAG-3' and reverse 5'-GCAGCCGCCACAAACATAC-3'; cyclin D1 forward 5'-GCTGCGAAGTGGAAACCATC-3' and reverse 5'-CCT CCTTCTGCACACATTTGAA-3'; cy tochrome $c$ oxidase 2 (COX2), forward 5'-CTGGCGCTCAGCCATACAG-3' and reverse 5'-CGCACTTATACTGGTCAAATCCC-3'; interleukin (IL)-8, forward 5'-CCTCCCCAGAATGTGACGC-3' and reverse 5'-CCCGCACACTCTTCCACTT-3'; tumor necrosis factor (TNF), forward 5'-AGGACGACTGTTCAG CACG-3' and reverse 5'-CCGGGCAACAATGTCCAA AAG-3'; FADD-like IL-1 $\beta$-converting enzyme-inhibitory protein (FLIP), forward 5'-AAGTCCTGACCAGTCGGA ACA-3' and reverse 5'-TCTTCAACGTGAGTCACCTTCT-3'; $\mathrm{X}$-linked inhibitor of apoptosis protein (XIAP), forward 5'-ACCGTGCGGTGCTTTAGTT-3' and reverse 5'-TGCGTG GCACTATTTTCAAGATA-3'; MYC, forward 5'-CAATCG GGCTGGTACTTGGAG-3' and reverse 5'-CGTGGGTGT AAGAAGACCTAGA-3'; BCL2L1, forward 5'-TTGCCAGCC GGAACCTATG-3' and reverse 5'-CGAAGGCGACCAGCA ATGATA-3'; GAPDH, forward 5'-GCACCGTCAAGGCTG AGAAC-3' and reverse 5'-TGGTGAAGACGCCAGTGGA-3'.

Western blotting. C33A cells were incubated with $10 \mu \mathrm{l} / \mathrm{ml}$ protease inhibitor cocktail (Sigma-Aldrich; Merck KGaA) and radioimmunoprecipitation assay buffer (Invitrogen; Thermo Fisher Scientific, Inc.) on ice for $20 \mathrm{~min}$ to extract protein. Following centrifugation at $12,000 \mathrm{x}$ g for $5 \mathrm{~min}$ at $4^{\circ} \mathrm{C}$, the supernatant was moved to a new Eppendorf tube and quantified using a Bicinchoninic Acid protein assay kit (Beyotime Institute of Biotechnology, Shanghai, China). A total of $40 \mu \mathrm{g}$ protein was separated by $10 \%$ SDS-PAGE and transferred to a PVDF membrane. Following blocking with 5\% skimmed milk for $1 \mathrm{~h}$, the membrane was incubated with primary antibodies 

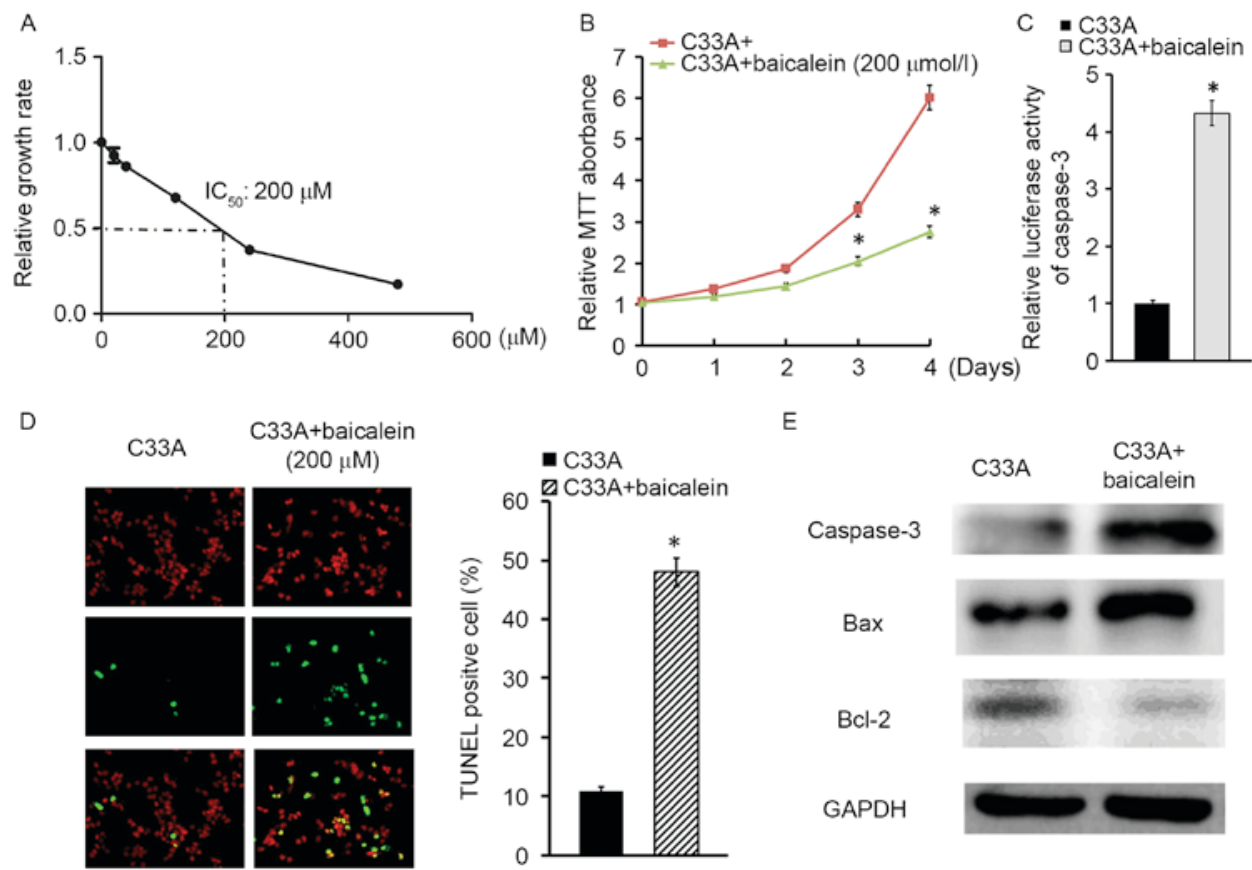

Figure 1. Baicalein suppressed C33A cell proliferation and induced cell apoptosis. (A) $\mathrm{IC}_{50}$ of baicalein on C33A. (B) C33A cell viability detected by MTT assay. (C) Caspase-3 activity tested by luciferase assay. (D) C33A cell apoptosis evaluated by the terminal deoxynucleotidyl transferase (TdT) dUTP nick-end labeling assay. (E) Apoptosis-associated protein expression detected by western blotting. ${ }^{*} \mathrm{P}<0.05$ vs. control.

against caspase-3 (1:500; ab13847; Abcam, Cambridge, MA, USA), B-cell lymphoma-2-associated X (bax; 1:500; ab32503; Abcam), bcl-2 (ab692, dilution 1:500; Abcam), p21 (ab109199, dilution 1:500, Abcam), Bim (1:500; ab7888; Abcam), cyclin D1 (1:500; ab134175; Abcam), phosphorylated (p)-Rb (S780; 1:500; ab47763; Abcam), Rb (ab181616, dilution 1:500; Abcam), p65 (1:500; ab16502, Abcam), p-p65 (S536; 1:500; ab86299; Abcam), p84 (1:500; ab102684; Abcam), elongation factor-1a (1:500; sc-21758; Santa Cruz Biotechnology, Inc., Dallas, TX, USA), GAPDH (1:500; ab8245; Abcam) at $4^{\circ} \mathrm{C}$ overnight. Subsequently, the membrane was incubated with the horseradish peroxidase conjugated anti-mouse (ab131368) or anti-rabbit (ab191866) secondary antibodies (dilution 1:2,000; Abcam) at $37^{\circ} \mathrm{C}$ for $30 \mathrm{~min}$ and was washed with PBS with $0.05 \%$ Tween-20. The protein bands were then visualized using enhanced chemiluminescence reagent (Thermo Fisher Scientific, Inc.). Gray value of the bands was analyzed by Image $\mathbf{J} 2 \mathrm{x}$ software. All experiments were repeated for three times.

Annexin V/PI assay. Following treatment with baicalein or SN50 (Biomol GmbH, Hamburg, Germany) for 24 h, C33A cells were collected and washed with PBS twice. Then the cells were resuspended in $400 \mu 1 \mathrm{X}$ binding buffer and added with $5 \mu \mathrm{l}$ Annexin V-FITC in the dark for $15 \mathrm{~min}$. PI $(10 \mu \mathrm{l})$ was then added and the cells were incubated in the dark for $5 \mathrm{~min}$. The cells were then tested for early and late apoptosis on flow cytometry. The results were analyzed using CellQuest software v3.3 (BD Biosciences, Franklin Lakes, NJ, USA). All experiments were repeated three times.

Statistical analysis. All data were presented as the mean \pm standard deviation and analyzed by SPSS software, version 19.0 (IBM Corp., Armonk, NY,USA). Data comparison was performed using Student's t-test or one-way analysis of variance. $\mathrm{P}<0.05$ was considered to indicate a statistically significant difference.

\section{Results}

Baicalein inhibited C33A proliferation and induced cell apoptosis. To investigate the effect of baicalein on cervical cancer cell C33A, the IC50 of baicalein was investigated, and was identified to be $200 \mu \mathrm{M}$ (Fig. 1A). Thus, $200 \mu \mathrm{M}$ baicalein was applied to treat $\mathrm{C} 33 \mathrm{~A}$ cells for different durations. The MTT assay observed that $\mathrm{C} 33 \mathrm{~A}$ cell proliferation was significantly slowed by baicalein in a time-dependent manner $(\mathrm{P}<0.05$; Fig. 1B). To further explore the pro-apoptotic effect of baicalein on cervical cancer, caspase-3 activity detection assay demonstrated that baicalein enhanced luciferase activity of caspase-3 in C33A cells compared with normal control cells (Fig. 1C). In addition, the TUNEL assay indicated that C33A apoptosis was upregulated following baicalein treatment for $24 \mathrm{~h}$ (Fig. 1D). In addition, Bax and caspase- 3 expression were increased, while Bcl-2 levels were downregulated in C33A cells following exposure to baicalein for $24 \mathrm{~h}$ (Fig. 1E). Taken together, baicalein may inhibit C33A proliferation and promote cell apoptosis.

Baicalein blocked C33A cell cycle. Due to the fact that cell viability and apoptosis were associated with the cell cycle, the current study investigated whether baicalein impacts the C33A cell cycle. Flow cytometry indicated that compared with the control, cell content apparently increased in $G_{0} / G_{1}$ phases and declined in $\mathrm{S}$ phase following $200 \mu \mathrm{M}$ baicalein intervention for $24 \mathrm{~h}$ (Fig. 2A). Furthermore, cell cycle-associated gene expression in $\mathrm{C} 33 \mathrm{~A}$ cells treated by baicalein was investigated. P21 and Bim significantly upregulated, while cyclin D1 markedly reduced at mRNA and protein 
A

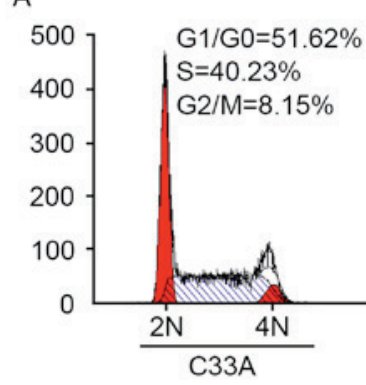

C

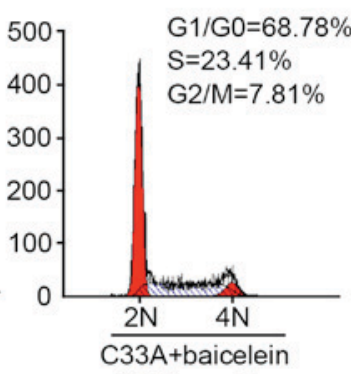

$(200 \mu \mathrm{mol} / \mathrm{l})$

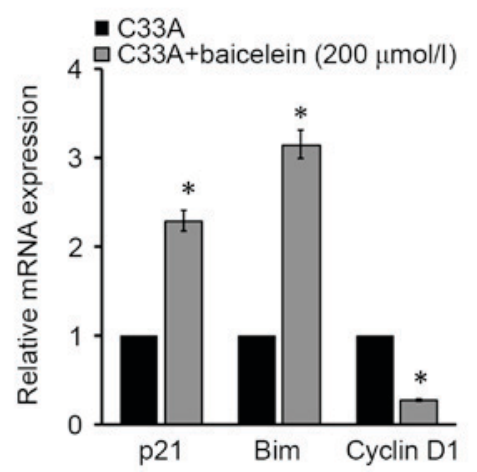

B

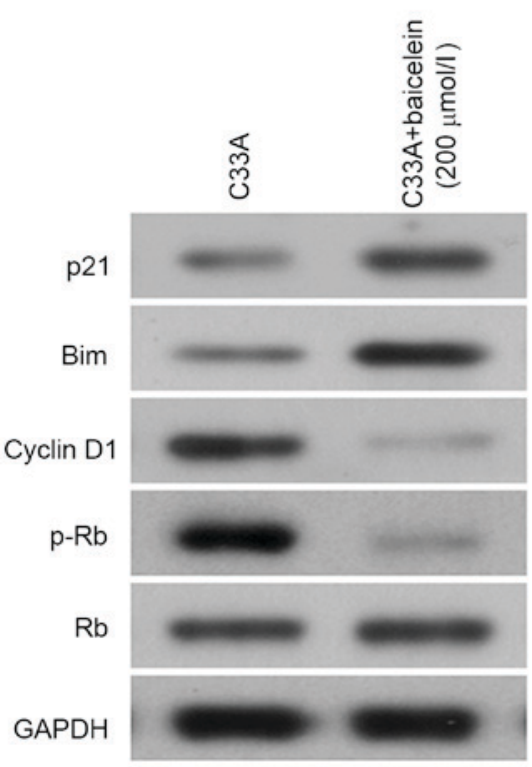

Figure 2. Baicalein blocked C33A cell cycle. (A) C33A cell cycle determined by flow cytometry. (B) Cell cycle-associated protein expression as detected by western blotting. (C) Cell cycle mRNA level tested by reverse transcription-quantitative polymerase chain reaction. ${ }^{*} \mathrm{P}<0.05$ vs. control. Bim, Bcl-2-like protein 11; p-, phosphorylated.

levels in $\mathrm{C} 33 \mathrm{~A}$ cells following treatment with baicalein (Fig. 2B and C). In addition, Rb phosphorylation levels were observed to be reduced under the effects of baicalein (Fig. 2B), suggesting that baicalein may restrain the cell cycle in cervical cancer.

Baicalein affected the $N F-\kappa B$ signaling pathway. To investigate which signaling pathway was involved in C33A treated with baicalein, the mRNAs activated by baicalein and control group was explored. The results indicated that the $\mathrm{NF}-\kappa \mathrm{B}$ pathway may be associated with the process due to the fact that NF- $\kappa \mathrm{B}$-associated genes, including TNF, interferon $\gamma$, B cell leukemia/lymphoma 2 related protein A1a, CFS1-like protein, and baculoviral IAP repeat containing 3 were downregulated in C33A following baicalein intervention (Fig. 3A). Subsequently, a variety of genes that may be associated with cervical cancer progress were investigated, and it was identified that numerous genes were downregulated after baicalein intervention, including COX2, IL-8, TNF, FLIP and XIAP (Fig. 3B). Due to the fact that these factors were predominantly regulated by the $\mathrm{NF}-\kappa \mathrm{B}$ signaling pathway, the influence of baicalein on the $\mathrm{NF}-\kappa \mathrm{B}$ signaling pathway was further investigated. The luciferase assay indicated that $\mathrm{NF}-\kappa \mathrm{B}$ activity was markedly reduced in C33A cells treated with baicalein (Fig. 3C). In addition, protein was extracted from C33A cells, and it was separated into the nucleus and cytoplasm. Western blot analysis exhibited that $\mathrm{NF}-\kappa \mathrm{B}$ p 65 protein levels were significantly reduced, while p84 expression in the nucleus was reduced in the baicalein group (Fig. 3D). It indicated that baicalein may suppress the activity of the $\mathrm{NF}-\kappa \mathrm{B}$ signaling pathway in cervical cancer cell C33A.
$N F-\kappa B$ signaling pathway mediated baicalein in inducing $C 33 A$ apoptosis. To discuss the role of $\mathrm{NF}-\kappa \mathrm{B}$ signaling pathway in the apoptosis-inducing effect of baicalein, SN50, a specific inhibitor of $\mathrm{NF}-\kappa \mathrm{B}$ signaling pathway, was used for investigation.pP65 expression was measured in C33A following treatment with baicalein and SN50. The results demonstrated that SN50 effectively suppressed p65 phosphorylation in C33A following baicalein induction (Fig. 4A). In addition, the MTT assay indicated that $\mathrm{C} 33 \mathrm{~A}$ proliferation was not significantly restrained by SN50 (P>0.05; Fig. 4B). Apoptosis assay indicated that C33A apoptosis was not affected by SN50 (Fig. 4C). Taken together, baicalein may inhibit $\mathrm{C} 33 \mathrm{~A}$ proliferation and promote cell apoptosis by the inhibiting $\mathrm{NF}-\kappa \mathrm{B}$ pathway.

\section{Discussion}

As a major form of programmed cell death, cell apoptosis serves a crucial role in maintaining cell stability to mediate organism growth and development. Normal apoptotic mechanisms are evaded in a variety of cancer cells, leading to uninhibited growth. Therefore, apoptosis has become a focus in life-science research, particularly in tumor research (17). The regulation of apoptosis is a complicated process predominantly triggered by two pathways, the intrinsic mitochondrial pathway and the extrinsic cell-death receptor pathway (18). In addition, the two pathways also have various intersections and may be regulated by a number of factors.

One of the major mechanisms of anticancer drug activity is to restrain cancer cell growth. The MTT assay results indicated that baicalein inhibited the growth of $\mathrm{C} 33 \mathrm{~A}$ cells in a time-dependent manner. Apoptotic cells exhibited biochemical and morphological changes, while they may reflect different stages of apoptosis. 
A

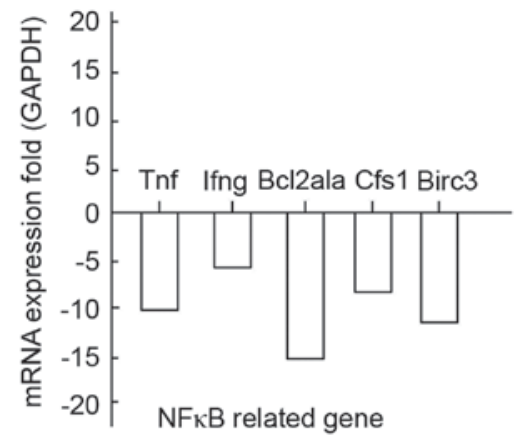

C

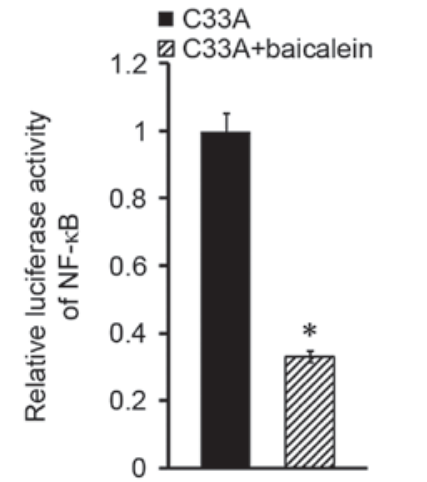

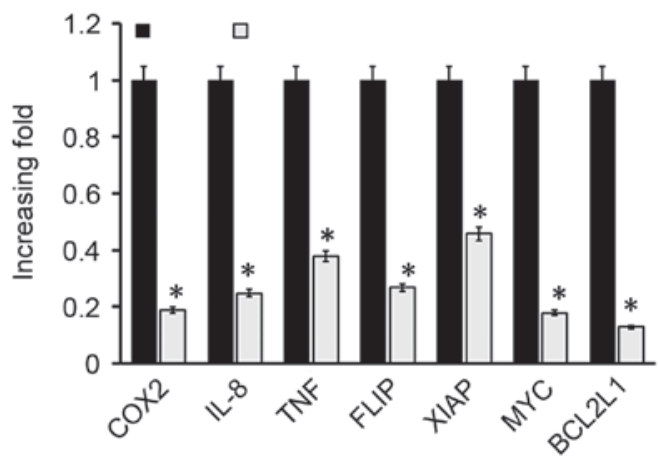

D

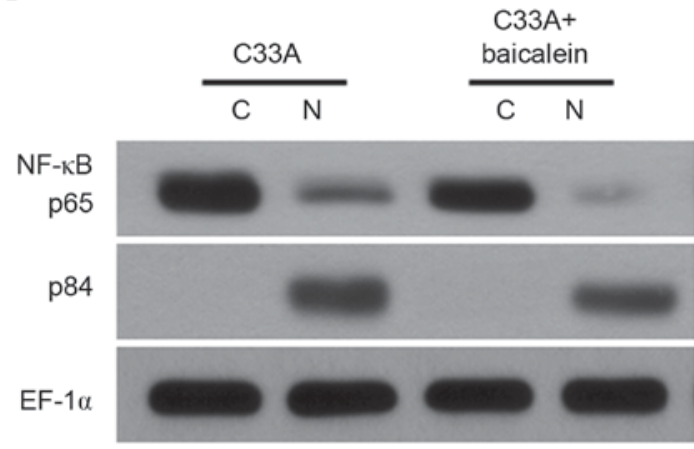

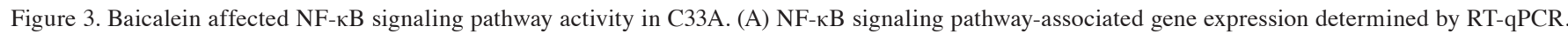
(B) Cervical cancer-associated gene expression measured by RT-qPCR. (C) NF- $\kappa$ B activity evaluated by the luciferase assay. (D) NF- $\mathrm{kB}$ nuclear translocation examined by western blotting. "P<0.05 vs. the control. NF- $\kappa B$, nuclear factor $\kappa \mathrm{B}$; RT-qPCR, reverse transcription-quantitative polymerase chain reaction; TNF, tumor necrosis factor; Ifng, interferon $\gamma$; Bcl2ala, B cell leukemia/lymphoma 2 related protein A1a; Cfs1, Cfs1-like protein; Birc3, baculoviral IAP repeat containing 3; COX2, cytochrome $c$ oxidase 2; IL-8, interleukin 8; FLIP, FLICE-like inhibitory protein; XIAP, X-linked inhibitor of apoptosis protein.

A

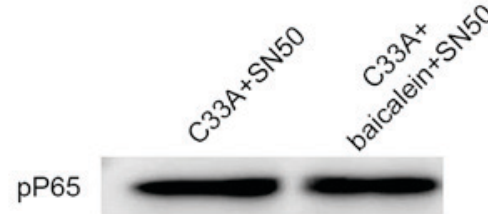

GAPDH
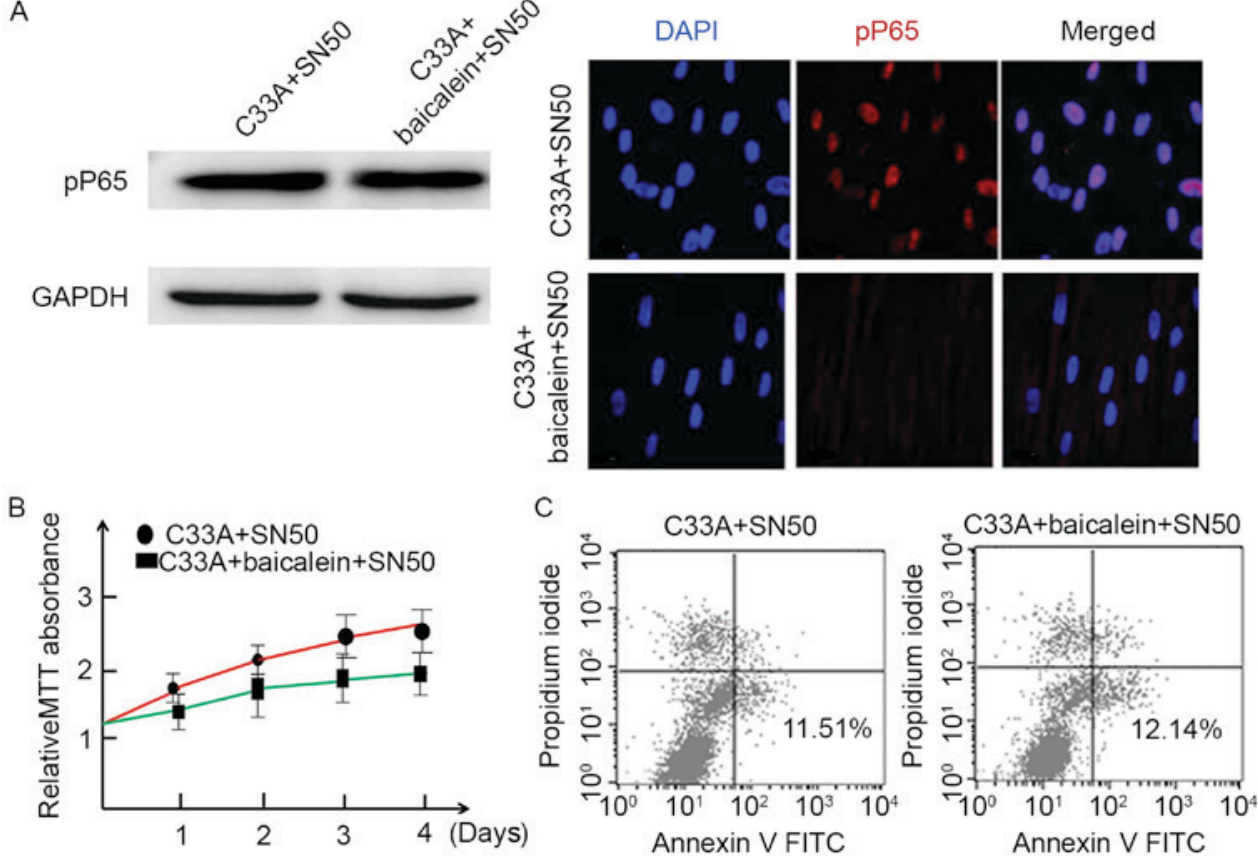

Figure 4. Nuclear factor $\mathrm{\kappa B}$ signaling pathway mediated baicalein in inducing C33A apoptosis. (A) P65 phosphorylation determined by western blotting and immunofluorescence. (B) Cell viability detected by MTT assay. (C) Cell apoptosis evaluated by flow cytometry. FITC, fluorescein isothiocyanate.

In the present study, the TUNEL assay identified cells with strand breakage using biotinylated nucleotides and subsequent immunodetection to label DNA strands. However, apoptosis is not the only situation where DNA strands are broken (19). It has been reported that baicalein induced cell apoptosis through activating caspase-9/-3 (15). Therefore, caspase-3 activity and expression 
was further detected in C33A cells upon baicalein treatment. Caspase- 3 is cleaved from procaspase- 3 and poly (ADP-ribose) polymerase is cut at Asp216-Gly217 once activated, thus splitting DNA between nucleosome to induce cell apoptosis (20). The results indicated that baicalein treatment significantly elevated the luciferase activity of caspase- 3 and caspase- 3 expression as compared with the untreated control group. Together with Bax and $\mathrm{Bcl}-2$ expression detection the apoptotic role of baicalein in cervical cancer was confirmed.

Cell cycle regulation is regulated various factors, including CDKs, Bim, p21 and the RB gene. A large number of studies have illustrated the relevance of cell cycle dysregulation in different types of human cancer $(21,22)$. Although it has been reported that baicalein can arrest cell cycle at several checkpoints depending on the type of cancer, few studies have investigated the role of baicalein in the cervical cancer cell cycle. The current study demonstrated that baicalein can regulate $\mathrm{C} 33 \mathrm{~A}$ cell distribution in the cell cycle, particularly by increasing the percentage of cells in the $G_{0} / G_{1}$ phase while decreasing the percentage of cells in the $\mathrm{S}$ phase.

To further investigate the potential mechanism of baicalein on the cell cycle, the expression of cyclin D1, p21 and the $\mathrm{Rb}$ levels were measured in $\mathrm{C} 33 \mathrm{~A}$ cells following baicalein treatment. As a key mediator of the $G_{1}$ checkpoint, cyclin D1 is expressed predominantly at the early stage of $\mathrm{G}_{1}$ phase. After that, cyclin D1/CDK4/6 forms a complex regulated by $\mathrm{Rb}$ phosphorylation (23-25). A previous study exhibited that $\mathrm{Rb}$ expression and phosphorylation serve important roles in regulation of the cell cycle $(26,27)$. The results indicated that baicalein decreased cyclin D1 and p21 expression at both mRNA and protein levels. Furthermore, Rb phosphorylation was also reduced upon baicalein treatment. These results may elucidate the impact of baicalein on $\mathrm{G}_{1}$ arrest. However, further investigation is required in order to clarify the specific mechanism of baicalein on the cell cycle.

The NF- $\kappa \mathrm{B}$ signaling pathway is considered to be associated with multiple cell functions. During inactivation, $N F-\kappa B$ locates in the cytosol and is bound to inhibitory $\mathrm{I} \kappa \mathrm{B}$ protein, which shields the nuclear localization signal. The complex enters the nucleus and binds to its consensus sequence to activate its downstream genes upon stimulation (28). In the present study, the $\mathrm{NF}-\kappa \mathrm{B}$ signaling pathway inhibitor SN50 was used to treat $\mathrm{C} 33 \mathrm{~A}$ cells, and it was identified that $\mathrm{P} 65$ phosphorylation and nuclear translocation were significantly blocked in C33A cells induced by baicalein. The influence of $\mathrm{NF}-\kappa \mathrm{B}$ signaling pathway on cell apoptosis is complex. Although $\mathrm{NF}-\kappa \mathrm{B}$ activation is thought to be part of the apoptotic induction, numerous studies have demonstrated that $\mathrm{NF}-\kappa \mathrm{B}$ is an anti-apoptotic response in the majority of circumstances (29-31). As one of the major components of death ligands, downregulation of c-FLIP weakens caspase- 8 inhibition and increases apoptosis (32). XIAP has been reported to evoke a second wave of $N F-\kappa B$ activation following $\mathrm{TNF} \alpha$ stimulation (33). COX, which can represent mitochondrial respiratory function, is also regulated by $\mathrm{NF}-\kappa \mathrm{B}$ (34). In the present study, cervical cancer cell apoptosis was significantly enhanced with FLIP, XIAP and COX2 downregulation. In addition, application of SN50 markedly restrained baicalein impact on C33A cell apoptosis and proliferation. These results indicated that baicalein may prevent cervical cancer cell apoptosis through modulating NF- $\mathrm{B}$ dependent survival pathway. In the present study, it was indicated that baicalein treatment decreased the luciferase activity of $\mathrm{NF}-\kappa \mathrm{B}$ in $\mathrm{C} 33 \mathrm{~A}$ cells. In addition, the active form of $\mathrm{NF}-\kappa \mathrm{B}, \mathrm{p} 65$ protein, expression in the nucleus markedly reduced under baicalein stimulation. It suggested that baicalein treatment markedly attenuated the NF- $\kappa \mathrm{B}$ activation through inhibition of NF- $\mathrm{B}$ nuclear translocation degradation and subsequently induced cervical cancer apoptosis.

Flavonoids are structurally similar to steroid hormones, particularly estrogens, and therefore have been studied for their potential effects on hormone-dependent cancer. Baicalein is a member of the flavonoid family, and its estrogen-mediated effects have been reported in multiple studies (35-37). Baicalein and other extracts have been previously observed to halt the cell cycle during the $\mathrm{S}$ and $\mathrm{G}_{2} / \mathrm{M}$-phases in MCF-7 human breast cancer cells by suppressing $17 \beta$-estradiol-induced transactivation of estrogen receptor $\alpha(37,38)$. Baicalein inhibited E2-induced migration, adhesion and invasion by interfering with $17 \beta$-estradiol (E2)-induced novel G protein-coupled estrogen receptor-associated signaling (39). Baicalein inhibits lipopolysaccharide-induced inflammatory cytokine production via regulation of the NF-kB pathway and estrogen-like activity, suggesting that it may be useful for preventing inflammation-associated diseases (40). However, the estrogen-like activity of baicalein in inhibiting cervical cancer requires further investigation.

In summary, C33A cell proliferation was suppressed by baicalein in a time-dependent manner. Baicalein induced the apoptosis of C33A cells, as indicated by the results of the TUNEL assay and caspase- 3 activity. Baicalein may induce apoptosis through blocking the cell cycle and $\mathrm{NF}-\kappa \mathrm{B}$ signaling pathway. These results indicated that baicalein may be a promising agent for treating patients with cervical cancer. Further in-depth studies are required to explore the molecular mechanisms of the anti-cancer characteristics of baicalein on cervical cancer.

\section{Acknowledgements}

The present study was supported by The Fund of Science and Technology Department of Sichuan province (grant no. 14JC01353-LH67), The Mutual Fund of Science and Technology Department of Sichuan Province [grant no. 2015LZCYD-S02(1/11)], The Fund of Education Department of Sichuan Province (grant no. 16ZB0195) and The Fund of Science and Technology Department of Luzhou City (grant no. 2014-S-35).

\section{References}

1. Shweel MA, Abdel-Gawad EA, Abdel-Gawad EA, Abdelghany HS, Abdel-Rahman AM and Ibrahim EM: Uterine cervical malignancy: Diagnostic accuracy of MRI with histopathologic correlation. J Clin Imaging Sci 2: 42, 2012.

2. Di Domenico F, Foppoli C,Coccia R and Perluigi M: Antioxidants in cervical cancer: Chemopreventive and chemotherapeutic effects of polyphenols. Biochim Biophys Acta 1822: 737-747, 2012.

3. Li J, Feng J, Luo C, Herman HY and Jiang RW: Absolute configuration of podophyllotoxone and its inhibitory activity against human prostate cancer cells. Chin J Nat Med 13: 59-64, 2015.

4. Mandal SK, Biswas R, Bhattacharyya SS, Paul S, Dutta S, Pathak S and Khuda-Bukhsh AR: Lycopodine from Lycopodium clavatum extract inhibits proliferation of HeLa cells through induction of apoptosis via caspase-3 activation. Eur J Pharmacol 626: 115-122, 2010. 
5. Park SE, Yoo HS, Jin CY, Hong SH, Lee YW, Kim BW, Lee SH, Kim WJ, Cho CK and Choi YH: Induction of apoptosis and inhibition of telomerase activity in human lung carcinoma cells by the water extract of Cordyceps militaris. Food Chem Toxicol 47: $1667-1675,2009$.

6. Ling Y, Chen Y, Chen P, Hui H, Song X, Lu Z, Li C, Lu N and Guo Q: Baicalein potently suppresses angiogenesis induced by vascular endothelial growth factor through the $\mathrm{p} 53 / \mathrm{Rb}$ signaling pathway leading to G1/S cell cycle arrest. Exp Biol Med (Maywood) 236: 851-858, 2011.

7. Chang WT, Lai TH, Chyan YJ, Yin SY, Chen YH, Wei WC and Yang NS: Specific medicinal plant polysaccharides effectively enhance the potency of a DC-based vaccine against mouse mammary tumor metastasis. PLoS One 10: e0122374, 2015.

8. Bodeker G: Integrative oncology meets immunotherapy: New prospects for combination therapy grounded in Eastern medical knowledge. Chin J Integr Med 18: 652-662, 2012.

9. Zhao Y, Liu X and Lu YX: MicroRNA-143 regulates the proliferation and apoptosis of cervical cancer cells by targeting HIF-1 $\alpha$. Eur Rev Med Pharmacol Sci 21: 5580-5586, 2017.

10. Ahmadi F, Ghasemi-Kasman M, Ghasemi S, Gholamitabar Tabari M, Pourbagher R, Kazemi S and Alinejad-Mir A: Induction of apoptosis in HeLa cancer cells by an ultrasonic-mediated synthesis of curcumin-loaded chitosan-alginate-STPP nanoparticles. Int J Nanomedicine 12: 8545-8556, 2017.

11. Huang WH, Lee AR, Chien PY and Chou TC: Synthesis of baicalein derivatives as potential anti-aggregatory and anti-inflammatory agents. J Pharm Pharmacol 57: 219-225, 2005.

12. Tsang PW, Chau KY and Yang HP: Baicalein exhibits inhibitory effect on the energy-dependent efflux pump activity in non-albicans Candida fungi. J Chemother 27: 61-62, 2015.

13. Luo R, Wang J, Zhao L, Lu N, You Q, Guo Q and Li Z: Synthesis and biological evaluation of baicalein derivatives as potent antitumor agents. Bioorg Med Chem Lett 24: 1334-1338, 2014

14. Song L, Yang H, Wang HX, Tian C, Liu Y, Zeng XJ, Gao E, Kang YM, Du J and Li HH: Inhibition of 12/15 lipoxygenase by baicalein reduces myocardial ischemia/reperfusion injury via modulation of multiple signaling pathways. Apoptosis 19: 567-580, 2014

15. Liu H, Dong Y, Gao Y, Du Z, Wang Y, Cheng P, Chen A and Huang $\mathrm{H}$ : The fascinating effects of baicalein on cancer: A review. Int J Mol Sci 17: E1681, 2016.

16. Livak KJ and Schmittgen TD: Analysis of relative gene expression data using real-time quantitative PCR and the 2(-Delta Delta C(T)) method. Methods 25: 402-408, 2001

17. Kim HG, Song H, Yoon DH, Song BW, Park SM, Sung GH, Cho JY, Park HI, Choi S, Song WO, et al: Cordyceps pruinosa extracts induce apoptosis of HeLa cells by a caspase dependent pathway. J Ethnopharmacol 128: 342-351, 2010.

18. Kim R: Recent advances in understanding the cell death pathways activated by anticancer therapy. Cancer 103: 1551-1560, 2005.

19. Singh SS, Mehedint DC, Ford OH III, Jeyaraj DA, Pop EA Maygarden SJ, Ivanova A, Chandrasekhar R, Wilding GE and Mohler JL: Comparison of ACINUS, caspase-3, and TUNEL as apoptotic markers in determination of tumor growth rates of clinically localized prostate cancer using image analysis. Prostate 69: 1603-1610, 2009

20. Lyakhovich A and Surrallés J: Constitutive activation of caspase- 3 and Poly ADP ribose polymerase cleavage in fanconi anemia cells. Mol Cancer Res 8: 46-56,2010.

21. Gasparri F, Ciavolella A and Galvani A: Cell-cycle inhibitor profiling by high-content analysis. Adv Exp Med Biol 604 137-148, 2007.

22. Wachtel M and Schäfer BW: Targets for cancer therapy in childhood sarcomas. Cancer Treat Rev 36: 318-327, 2010.

23. Blagosklonny MV and Pardee AB: The restriction point of the cell cycle. Cell Cycle 1: 103-110, 2002.

24. Giacinti $\mathrm{C}$ and Giordano A: RB and cell cycle progression. Oncogene 25: 5220-5227, 2006.
25. Caldon CE, Sutherland RL and Musgrove E: Cell cycle proteins in epithelial cell differentiation: Implications for breast cancer. Cell Cycle 9: 1918-1928, 2010

26. Merli M, Benassi MS, Gamberi G, Ragazzini P, Sollazzo MR Molendini L, Magagnoli G, Ferrari C, Maltarello MC and Picci P. Expression of G1 phase regulators in MG-63 osteosarcoma cell line. Int J Oncol 14: 1117-1121, 1999.

27. Broceño C, Wilkie $S$ and Mittnacht S: RB activation defect in tumor cell lines. Proc Natl Acad Sci USA 99: 14200-14205, 2002.

28. Tak PP and Firestein GS: NF-kappaB: A key role in inflammatory diseases. J Clin Invest 107: 7-11, 2001.

29. Choi $\mathrm{C}$ and Benveniste EN: Fas ligand/Fas system in the brain: Regulator of immune and apoptotic responses. Brain Res Brain Res Rev 44: 65-81, 2004.

30. López-Huertas MR, Mateos E, Sánchez Del Cojo M, Gómez-Esquer F, Díaz-Gil G, Rodríguez-Mora S, López JA, Calvo E, López-Campos G, Alcamí J and Coiras M: The presence of HIV-1 Tat protein second exon delays fas protein-mediated apoptosis in CD4+ T lymphocytes: A potential mechanism for persistent viral production. J Biol Chem 288: 7626-7644, 2013

31. Qin Y, Camoretti-Mercado B, Blokh L, Long CG, Ko FD and Hamann KJ: Fas resistance of leukemic eosinophils is due to activation of NF-kappa B by Fas ligation. J Immunol 169: 3536-3544, 2002

32. Yang JK: FLIP as an anti-cancer therapeutic target. Yonsei Med J 49: 19-27, 2008.

33. Winsauer G, Resch U, Hofer-Warbinek R, Schichl YM and de Martin R: XIAP regulates bi-phasic NF-kappaB induction involving physical interaction and ubiquitination of MEKK2 Cell Signal 20: 2107-2112, 2008

34. Hao CM, Yull F, Blackwell T, Kömhoff M, Davis LS and Breyer MD: Dehydration activates an NF-kappaB-driven, COX2-dependent survival mechanism in renal medullary interstitial cells. J Clin Invest 106: 973-982, 2000.

35. Zhu JT, Choi RC, Chu GK, Cheung AW, Gao QT, Li J, Jiang ZY, Dong TT and Tsim KW: Flavonoids possess neuroprotective effects on cultured pheochromocytoma PC12 cells: A comparison of different flavonoids in activating estrogenic effect and in preventing beta-amyloid-induced cell death. J Agric Food Chem 55: 2438-2445, 2007.

36. So FV, Guthrie N, Chambers AF and Carroll KK: Inhibition of proliferation of estrogen receptor-positive MCF-7 human breast cancer cells by flavonoids in the presence and absence of excess estrogen. Cancer Lett 112: 127-133, 1997.

37. Po LS, Chen ZY, Tsang DS and Leung LK: Baicalein and genistein display differential actions on estrogen receptor (ER) transactivation and apoptosis in MCF-7 cells. Cancer Lett 187: 33-40, 2002.

38. Wang CZ, Li XL, Wang QF, Mehendale SR and Yuan CS: Selective fraction of Scutellaria baicalensis and its chemopreventive effects on MCF-7 human breast cancer cells. Phytomedicine 17: 63-68, 2010.

39. Shang D, Li Z, Zhu Z, Chen H, Zhao L, Wang X and Chen Y: Baicalein suppresses 17- $\beta$-estradiol-induced migration, adhesion and invasion of breast cancer cells via the $\mathrm{G}$ protein-coupled receptor 30 signaling pathway. Oncol Rep 33: 2077-2085, 2015.

40. Fan GW, Zhang Y, Jiang X, Zhu Y, Wang B, Su L, Cao W, Zhang $\mathrm{H}$ and Gao X: Anti-inflammatory activity of baicalein in LPS-stimulated RAW264.7 macrophages via estrogen receptor and NF- $\mathrm{BB}$-dependent pathways. Inflammation 36: 1584-1591, 2013.

This work is licensed under a Creative Commons Attribution-NonCommercial-NoDerivatives 4.0 International (CC BY-NC-ND 4.0) License. 